\title{
A review of Palearctic Teuchophorus Loew (Diptera: Dolichopodidae) with an updated catalog and revised key to species
}

\author{
Обзор палеарктических видов рода Tеисьорһorus Loew \\ (Diptera: Dolichopodidae) с уточнённым каталогом и \\ переработанным определителем видов
}

\author{
I.Ya. Grichanov ${ }^{1}$, O.P. Negrobov ${ }^{2}$ \& O.V. Selivanova ${ }^{2}$ \\ И.Я. Гричанов ${ }^{1}$, О.П. Негробов ${ }^{2}$, О.В. Селиванова ${ }^{2}$
}

\footnotetext{
${ }^{1}$ All-Russian Institute of Plant Protection, Podbelskiy roadway 3, St. Petersburg, Pushkin 196608, Russia. E-mail: grichanov@mail.ru

${ }^{2}$ Department of Ecology and Systematics of Invertebrate Animals, Biological-Soil Sciences Faculty, Voronezh State University, Universitetskaya sq. 1, Voronezh 394006, Russia. E-mail: ins285@bio.vsu.ru

Всероссийский институт защиты растений, шоссе Подбельского 3, Санкт-Петербург-Пушкин 196608, Россия

${ }^{2}$ Кафедра экологии и систематики беспозвоночных животных, биолого-почвенный факультет, Воронежский государственный университет, Университетская площадь 1, Воронеж 394006, Россия
}

KEY WORDS: Dolichopodidae, Teuchophorus, Palearctic, new species, key.

КЛЮЧЕВЫЕ СЛОВА: Dolichopodidae, Teuchophorus, Палеарктика, новый вид, определитель.

ABSTRACT. The genus Teuchophorus Loew, 1857 in the Palearctic Region is reviewed. It comprises 21 species including a new species Teuchophorus israelensis Grichanov, Negrobov et Selivanova sp.n. from Israel. The species is very close to $T$. chaetifemoratus Pollet et Kechev, 2007, differing from the latter in presence of 3-4 strong ventral bristles on mid tibia and ventral row of bristly hairs on hind tibia. An updated catalog and revised key to species of Palearctic Teuchophorus are provided.

РЕЗЮМЕ. Дан обзор палерктических видов рода Teuchophorus Loew, 1857. Он включает 21 вид, в том числе Teuchophorus israelensis Grichanov, Negrobov et Selivanova sp.n. из Израиля. Новый вид близок к T. chaetifemoratus Pollet et Kechev, 2007, отличаясь от него хетотаксией средних и задних голеней. Приведён каталог и определитель палеарктических видов рода.

\section{Introduction}

The Teuchophorus Loew, 1857 contains about 120 mainly Oriental species and one species described from Namibia, but also some Nearctic and Australasian species. The Palearctic fauna of the genus totals more than 20 species [Grichanov et al., 2011] inhabiting mainly temperate, Mediterranean and subtropical natural zones.

Negrobov et al. [1984] illustrated and keyed 13 then known Palearctic species of Teuchophorus with the exception of doubtful T. tenuemarginatus Strobl, 1909. Later four new species were described from Italy
[Meuffels \& Grootaert, 1992], Algeria [Grootaert et al., 1995], Bulgaria [Pollet \& Kechev, 2007] and Turkey [Naglis, 2009]. In addition, three new species were described from Chinese provinces located at the latitude $30^{\circ} \mathrm{N}$, i.e. near the border between Palearctic and Oriental Regions [Yang \& Saigusa, 2000; Yang, 2002]. Sympycnus hygropetricus Vaillant, 1952, was transferred to Teuchophorus and placed in synonymy to $T$. simplex Mik, 1880 [Meuffels \& Grootaert, 1986, 1992]. Female holotype of Sympycnus balearicus Tsacas, 1960 was examined and considered a member of Teuchophorus [Grichanov, 2008]. On the contrary, T. tenuemarginatus was recombined with Sympycnus Loew, 1857 and synonymized with $S$. simplicipes Becker, 1908 [Grichanov \& Tomkovich, 2009].

It is worth noting that some Chinese species (e.g., T. sinensis Yang et Saigusa, 2000, reported also from Korea) were described with relatively simple legs and with simple wing costa behind $\mathrm{R}_{1}$, a key character of Suschania Negrobov, 2003, an endemic genus in the Russian Far East (Primorskii Territory). Those species may belong to Suschania that has also such synapomorphy as distinct anterior curve at base of distal section of vein M. Some Oriental and Australasian Teuchophorus species with simple costa and/or modified legs are apparently paraphyletic to the typical $T$. spinigerellus clade, as it was already supposed recently [Lim et al., 2010; Grichanov et al., 2011]. They may belong to Suschania, Sympycnus, Telmaturgus Mik, 1874, to Mastigomyia Becker, 1924, and Olegonegrobovia Grichanov, 1995, erroneously synonymized with Teuchophorus by Meuffels and Grootaert [2004], to Paresus Wei, 2006, synonymized with the same genus by Yang et al. [2006]. On the other 
hand, we saw a male of probably undescribed Teuchophorus species from Algeria (ISNB) with simple costa, but with remarkably ornamented hind tibia.

\section{Material and methods}

The holotype and paratypes of the new species and other material cited are housed at the Department of Zoology, Tel Aviv University, Israel [TAU]; Royal Institute for Natural Sciences, Brussels, Belgium [ISNB]; Museum of Natural History, Paris, France [MNHP]; Natural History Museum, Berlin, Germany [MFN]; Voronezh State University, Voronezh, Russia [VSU]; Zoological Museum of Moscow State University, Moscow, Russia [ZMU].

Morphological terminology follows Grichanov [2007] and Cumming \& Wood [2009]. The relative lengths of the podomeres should be regarded as representative ratios and not measurements. Body length is measured from the base of the antenna to the tip of epandrium. Wing length is measured from the base to the wing apex. Male genitalia were not dissected and figured as they have low taxonomic value in the genus Teuchophorus. Information on world distribution for each species listed follows Grichanov [2003-2012]. Type localities are provided and country lists are arranged alphabetically.

\section{Systematics}

Genus Teuchophorus Loew, 1857

Teuchophorus Loew, 1857: 44; Pollet \& Kechev, 2007: 51; Grichanov et al., 2011: 35 .

TYPE SPECIES: Dolichopus spinigerellus Zetterstedt, 1843 (designation by Coquillett, 1910: 613).

DIAGNOSIS: Body small-sized; thoracic pleura dark; frons broad, narrowing towards antennae. 2 pairs of postverticals. In male, eyes often contiguous on face for a short distance; postpedicel more or less triangular; arista-like stylus dorsal; 5-6 pairs of strong dorsocentrals; acrostichals uniseriate or absent (exceptionally irregularly biseriate); male legs often modified and (or) adorned; male wing usually with costal callus (stigma) between tips of $\mathrm{R}_{1}$ and $\mathrm{R}_{2+3}$; crossvein $\mathrm{dm}-\mathrm{cu}$ joining $\mathrm{CuA}_{1}$ at distinctly oblique angle; apical section of $\mathrm{M}$ turned up immediately after dm-cu.

\section{Teuchophorus bipilosus Becker, 1908}

Teuchophorus bipilosus Becker, 1908: 47; Grootaert et al., 1995: 109 (redescription).

TYPE LOCALITY: Spain: Canary Is., Teneriffe.

TYPE MATERIAL EXAMINED. Paralectotypes: $20^{\top},+$, Canary Is., Teneriffe [VSU].

=Teuchophorus longipilus Strobl, in Czerny et Strobl, 1909: 187 (synonymized by Becker, 1918: 114, 116). Type locality: Spain: Algeciras.

=Teuchophorus cupreoobscurus Santos Abreu, 1929: 45 (as a var. of T. bipilosus); Negrobov, 1991: 63 (as subsp. of T. bipilosus). Type locality: Spain: Canary Is., Santa Cruz, La Palma.

DISTRIBUTION: Algeria, France, Portugal (Madeira), Russia (Krasnodar), Spain (incl. Canary Is.).

\section{Teuchophorus bisetus Loew, 1871}

Teuchophorus bisetus Loew, 1871: 58

TYPE LOCALITY: Uzbekistan: "Seravschan Thal, Turkestan" (originally published as "Samarkand et vallis fluminis Zeraphshan").
TYPE MATERIAL EXAMINED. Lectotype: $\oslash^{\Uparrow}$, "Seravschan Thal, Turkestan, N 12751" [ZMU]. Paralectotypes: $20^{\prime}$, same locality [MFN and ZMU]. Lectotype and paralectotypes are here designated to fix the current taxonomic concept and ensure consistent future interpretation.

MATERIAL EXAMINED. 20', Tajikistan: Parkhar dist., Dekhkonabad, 12 and 27.V.1981, Grichanov [VSU]; 10', Tajikistan: Dusti env., 2.VII.1985, Grichanov, Shamshev [VIZR].

REDESCRIPTION. Male. Body length 1.5-2.0 mm. Face greyish-white, in middle about half as wide as height of postpedicel. Frons shining green with violet reflection. Upper postocular bristles black, lateral and lower light yellow. Antenna black; postpedicel budlike, with short hairs, hardly longer than wide, with rounded apex; arista-like stylus dorsal; ratio of postpedicel length, width and arista, $0.3 / 0.2 / 1.7$. Palpi and proboscis dark-brown, with black hairs. Thorax green. Mesonotum shining green, grey pollinose, pleura densely grey pollinose. Legs yellow, tarsi infuscated from tip of basitarsi. Coxae with yellow hairs, hind coxa with dark outer bristle. All tarsi simple. Fore femur without long bristles, with short posteroventral bristle at apex. Fore tibia with short bristles, 3 antero-, 1 posterodorsal and 1 posteroventral. Length ratios of fore tibia and tarsomeres: $23 / 16 / 6 / 3 / 2 / 3$. Mid femur with two long unequal black and $2-3$ short yellow basoventral bristles; with one strong anterior and one strong posteroventral subapical bristles. Mid tibia with 2 long black ventral, 1 antero- and 2 posterodorsal bristles. Length ratios of mid tibia and tarsomeres: 25/17/5/4/3/4. Hind femur with short subapical bristle. Hind tibia thickened in distal half, with 2 strong black ventral bristles at 2/3,1 strong ventral bristle at apex, group of yellow ventral hairs in distal third and 3-4 short dorsal bristles. Length ratios of hind tibia and tarsomeres: $27 / 9 / 8 / 5 / 3 / 3$. Wings hardly darkened, with well developed stigma; $\mathrm{R}_{4+5}$ and $\mathrm{M}_{1+2}$ diverging distally; length ratio of costal section between $\mathrm{R}_{2+3}$ and $\mathrm{R}_{4+5}$ to that between $\mathrm{R}_{4+5}$ and $\mathrm{M}_{1+2}, 13 / 6$; ratio of $d m-c u$ to distal part of $\mathrm{CuA}_{1}, 4 /$ 13; anal angle blunt. Lower calypter yellow, with yellow cilia. Halter yellow. Abdomen green, grey pollinose laterally, with black bristles.

DISTRIBUTION: Iraq, Israel, Tajikistan, Turkey, Uzbekistan.

\section{Teuchophorus calcaratus (Macquart, 1827)}

Teuchophorus calcaratus (Macquart, 1827); Loew, 1857: 44. Medetera calcarata Macquart, 1827: 47.

TYPE LOCALITY: not given [France].

DISTRIBUTION: Austria, Azerbaijan, Belgium, Czech, France, Germany, Georgia, Hungary, Italy, Latvia, Lithuania, Luxembourg, Netherlands, Poland, Romania, Russia (Adygea, Alania, Kabardino-Balkaria, Krasnodar, Krasnoyarsk, Leningrad, Lipetsk, Mordovia, Moscow, Pskov, Vologda), Slovakia, Sweden [Roy Danielsson, pers. com.], Switzerland, UK.

\section{Teuchophorus chaetifemoratus Pollet et Kechev, 2007}

Teuchophorus chaetifemoratus Pollet et Kechev, 2007: 47. TYPE LOCALITY: Bulgaria: Plovdiv province, Rhodopes Mountains, Markovo.

DISTRIBUTION: Bulgaria, Turkey.

\section{Teuchophorus cristulatus Meuffels et Grootaert, 1992}

Teuchophorus cristulatus Meuffels et Grootaert, 1992: 131. TYPE LOCALITY: Italy: Sicily, prov. Trapani, Alkamo. DISTRIBUTION: Italy, Turkey. 
6. Teuchophorus gissaricus

Negrobov et Grichanov, 1982

Teuchophorus gissaricus Negrobov et Grichanov, 1982: 107. TYPE LOCALITY: Tajikistan: Gissar Ridge, Kondara Gorge. DISTRIBUTION: Tajikistan.

7. Teuchophorus monacanthus Loew, 1859

Teuchophorus monacanthus Loew, 1859: 21.

TYPE LOCALITY: not given.

MATERIAL EXAMINED. $1 \sigma^{7}$, Turkey: Antalya reg., R. Köprü (37.075N / 31.232E), 06.09.2009, leg. N. Dvoretskaya [ZMU].

DISTRIBUTION: Austria, Azerbaijan, Belgium, Bulgaria, Czech, Denmark, France, Georgia, Germany, Greece incl. Crete, Hungary, Iraq, Ireland, Israel, Italy, Latvia, Luxembourg, Netherlands, Norway, Poland, Romania, Russia (Adygea, Kabardino-Balkaria, Krasnodar, Leningrad, Lipetsk, Murmansk, Stavropol, Voronezh), Slovenia, Spain, Sweden, Switzerland, Turkey, UK, "Yugoslavia", "Middle Asia".

\section{Teuchophorus monochaetus}

Negrobov, Grichanov et Shamshev, 1984

Teuchophorus monochaetus Negrobov, Grichanov et Shamshev, 1984. TYPE LOCALITY: Tajikistan: Parkhar distr., Dekhkonabad. DISTRIBUTION: Tajikistan.

9. Teuchophorus nigrescus Yang et Saigusa, 2000

Teuchophorus nigrescus Yang et Saigusa, 2000: 206. TYPE LOCALITY: China: Henan, Luoshan, Lingshan Mountain DISTRIBUTION: China (Henan).

10. Teuchophorus nigricosta (von Roser, 1840)

Teuchophorus nigricosta (von Roser, 1840); Becker, 1918: 57. =Chrysotus nigricosta von Roser, 1840: 55 .

TYPE LOCALITY: not given (Germany: Württemberg).

=Teuchophorus pectinifer Kowarz, 1868: 218 (synonymized by Collin, 1940: 269 [as syn. of T. signatus (Zetterstedt, 1849)]). Type locality: "bei Eger, Franzensbad" [= Frantiskovy Lazne], "Losoncz" [= Lucenec].

=Chrysotus signatus Zetterstedt, 1849: 3065. Type locality: Denmark =Teuchophorus signatus (Zetterstedt, 1849); Kowarz, 1874: 476.

=Medeterus signatus (Zetterstedt, 1849).

=Teuchophorus signatus Becker, 1918: 117 ("Staeger ap. Zetterstedt, 1849, nec Zetterstedt, 1849"')

MATERIAL EXAMINED. $3 \sigma^{7}$, Sweden: Kristianstadt, 7.VII.2002, I. Grichanov [VIZR].

DISTRIBUTION: Austria, Belgium, Czech, Denmark, Estonia, Finland, France, Germany, Hungary, Italy, Netherlands, Poland, Romania, Russia (Krasnoyarsk, Leningrad, Lipetsk, Mordovia, Pskov), Slovakia, Sweden, Switzerland, UK.

\section{Teuchophorus pseudobipilosus Negrobov, Grich-} anov et Shamshev, 1984

Teuchophorus pseudobipilosus Negrobov, Grichanov et Shamshev, 1984: 40

TYPE LOCALITY: Tajikistan: Parkhar distr., Dekhkonabad.

DISTRIBUTION: Tajikistan.

12. Teuchophorus quadrisetosus Naglis, 2009

Teuchophorus quadrisetosus Naglis, 2009: 177.

TYPE LOCALITY: Turkey, Province Kars, Aras Valley, West Karakurt.

DISTRIBUTION: Turkey.

13. Teuchophorus rohdendorfi Stackelberg, 1927

Teuchophorus rohdendorfi Stackelberg, 1927: 231.

TYPE LOCALITY: Tadjikistan: "Pendzhikent, prov. Samarcandicae".

DISTRIBUTION: Tadjikistan, Kyrgyzstan. Erroneously assigned to Uzbekistan by Negrobov et al. [1984]
14. Teuchophorus rozkosnyi Olejnichek, 1981

Teuchophorus rozkosnyi Olejnichek, 1981: 3.

TYPE LOCALITY: Afghanistan: the Paghman river near Paghman. DISTRIBUTION: Afghanistan, Uzbekistan.

15. Teuchophorus samraouii

Grootaert, Stark et Meuffels, 1995

Teuchophorus samraouii Grootaert, Stark et Meuffels, 1995: 109.

TYPE LOCALITY: Algeria: El Kala.

DISTRIBUTION: Algeria.

\section{Teuchophorus simplex Mik, 1880}

Teuchophorus simplex Mik, 1880: 602.

=Sympycnus hygropetricus Vaillant, 1952: 6 (synonymized by Meuffels et Grootaert, 1992: 134). Type locality: France: “Alpes du Dauphine, a Domene".

=Teuchophorus hygropetricus (Vaillant, 1952); Meuffels et Grootaert, 1986: 217.

TYPE LOCALITY: Austria: Gmunden.

DISTRIBUTION: Austria, Belgium, Bulgaria, Czech, France, Germany, Greece, Hungary, Netherlands, Poland, Sweden, UK.

17. Teuchophorus sinensis Yang et Saigusa, 2000

Teuchophorus sinensis Yang et Saigusa, 2000: 205. tain.

TYPE LOCALITY: China: Henan, Luoshan, Lingshan Moun-

DISTRIBUTION: Palearctic: Korea, China (Henan, Zhejiang); Oriental: China (Sichuan, Zhejiang).

\section{Teuchophorus spinigerellus (Zetterstedt, 1843)}

Teuchophorus spinigerellus (Zetterstedt, 1843); Loew, 1857: 44.

=Porphyrops spinigerella (Zetterstedt, 1843); Haliday, in: Walker et al., 1851: 214.

=Dolichopus spinigerellus Zetterstedt, 1843: 604 .

TYPE LOCALITY: Suecia meridionali \& media, Scania ad Lund, Ostrogothia ad Wadstena, Dania [Sweden, Denmark].

DISTRIBUTION: Abkhazia, Austria, Azerbaijan, Belgium, Bulgaria, Czech, Denmark, Egypt; Estonia, Finland, France, Germany, Greece, Hungary, Ireland, Italy, S Kazakhstan, Latvia, Netherlands, Norway, Poland, Romania, Russia (Adygea, Kabardino-Balkaria, Kaluga, Krasnodar, Leningrad, Pskov, Stavropol', Vologda), Spain, Sweden, Switzerland, Turkey, UK.

19. Teuchophorus tianmushanus Yang, 2002

Teuchophorus tianmushanus Yang, 2002: 437.

TYPE LOCALITY: China: Zhejiang, Tianmushan.

DISTRIBUTION: Palearctic: China (Zhejiang); Oriental: China (Guangdong, Guizhou, Zhejiang)

20. Teuchophorus ussurianus

Negrobov, Grichanov et Shamshev, 1984

Teuchophorus ussurianus Negrobov, Grichanov et Shamshev, 1984: 37.

TYPE LOCALITY: Russia: Primorye, Suputinskii reserve.

DISTRIBUTION: China (Beijing), Japan, Russia (Primorskii Territory).

Doubtful species of Teuchophorus

Teuchophorus balearicus (Tsacas, 1960)

Teuchophorus balearicus (Tsacas, 1960); Grichanov, 2008: 45. =Sympycnus balearicus Tsacas, 1960:239. Type locality: Spain: Valldemosa, Majorca [= Mallorca].

TYPE MATERIAL EXAMINED. Holotype: + , Valdemosa, 9.IX.1958, L. Tsacas Sympycnus + balearicus n.sp. Type L. Tsacas 1959 / Type (red) [MNHP] 
Species excluded from Teuchophorus

Teuchophorus flavicoxa (Meigen, 1824); Bezzi, 1903: 347; Becker, 1918: 116, 117, 118 [synonym of Teuchophorus spinigerellus (Zetterstedt, 1843)?]; Parent, 1925: 52, 57 [synonym of Anepsiomyia flaviventris (Meigen, 1824)]

=Porphyrops flavicoxa Meigen, 1824: 57 .

Teuchophorus pectinulatus [Loew, 1864]: Negrobov, 1991: 62; Yang et al., 2006: 466 [in error in synonymy to Campsicnemus pumilio (Zetterstedt, 1843)].

Teuchophorus tenuemarginatus Strobl, in Czerny \& Strobl, 1909: 188; Grichanov \& Tomkovich, 2009: 108 (synonym of Sympycnus simplicipes Becker, 1908).

\section{Teuchophorus israelensis}

Grichanov, Negrobov et Selivanova sp.n. Figs 1-3

TYPE MATERIAL. Holotype: $\sigma^{7}$, Israel: Park HaYarden, 14.VI.1982, A. Freidberg. Paratypes: Israel: $30^{\top} \sigma^{\top}$, Park HaYarden, 18.VI.1982, A. Freidberg; O', Yavne'el, 24.VI.1981, M. Kaplan; $20^{7} 0^{7}$, Tel Dan, 7.VIII.1974, F. Nachbar [TAU].

DESCRIPTION. Male. Length (mm): body 1.6, antenna 0.7 , wing $2.9 / 0.65$, hypopygium 0.2 .

Head. Face with black ground colour, grey pollinose; distinctly narrowing towards clypeus, not reaching lower eye margin; at clypeus half as wide as postpedicel is high. Frons shining dark metallic blue, sides slightly dusted. Uppermost postocular bristles black, lower postoculars yellowish. Two pairs of postvertical bristles, about as long as postoculars. Vertical bristles strong, incline, inserted at level of posterior edge of ocellar tubercle. One pair of postocellar hairs. Palpus small, blackish brown, with brown pubescence and one strong apical brown bristle. Proboscis small, brown. Antenna entirely black; scape bare, pedicel with distal ring of setae; postpedicel with rounded apex and short pubescence, slightly higher than long, slightly longer than scape and pedicel combined; arista-like stylus dorsal, with short pubescence, 4.5 times longer than first three antennal segments combined.

Thorax. Mesonotum including scutellum shining dark bluish green. Pleura dark green, slightly dusted greyish. All bristles black. Lower propleura with 3 small black prothoracic setae; 6 pairs of dorsocentrals, nearly equal-sized; only medial pair of strong scutellar bristles present; acrostichals rather strong, irregularly biserial; scutellum with sparse marginal fringe of minute, white hairs.

Wing transparent, with dark veins and distinct costal stigma behind $R_{1}$. Proximal section of vein $M_{1+2} 0.7$ times as long as distal section. Proximal section of vein $\mathrm{CuA}_{1} 1.7$ times as long as distal section. Ratio of $d m-c u$ to distal part of $\mathrm{CuA}_{1}, 2 / 5$. Veins $\mathrm{R}_{4+5}$ and $\mathrm{M}_{1+2}$ parallel, slightly diverging at wing apex. $\mathrm{M}_{1+2}$ upturned immediately beyond $\mathrm{dm}-\mathrm{cu}$.

Legs (Figs 1-3) including coxae and trochanters yellow; coxae and tarsi from tip of basitarsi infuscated. Fore coxa with sparse pubescence and some brown apical bristles. Fore femur with two small av and one larger pv preapical bristles. Fore tibia simple, without dorsal bristles and with yellow apicoventral comb. Fore basitarsus with distinct ventral serration of inclined bristles, bristles not as long as tarsomere diameter. Length ratios of leg I: 40/33/20/9/6/5/5. Mid coxa with yellowish bristles on anterior face. Mid femur with two basoventral bristles at basal $1 / 6$, about as long as femur diameter, of which basal bristle finer; with one strong anterior and one strong posteroventral subapical bristles. Mid tibia with pair of antero- and posterodorsal bristles at basal fourth, 1 anterodorsal bristle at middle, with row of 3-4 strong ventrals (sometimes different number on left and right legs);

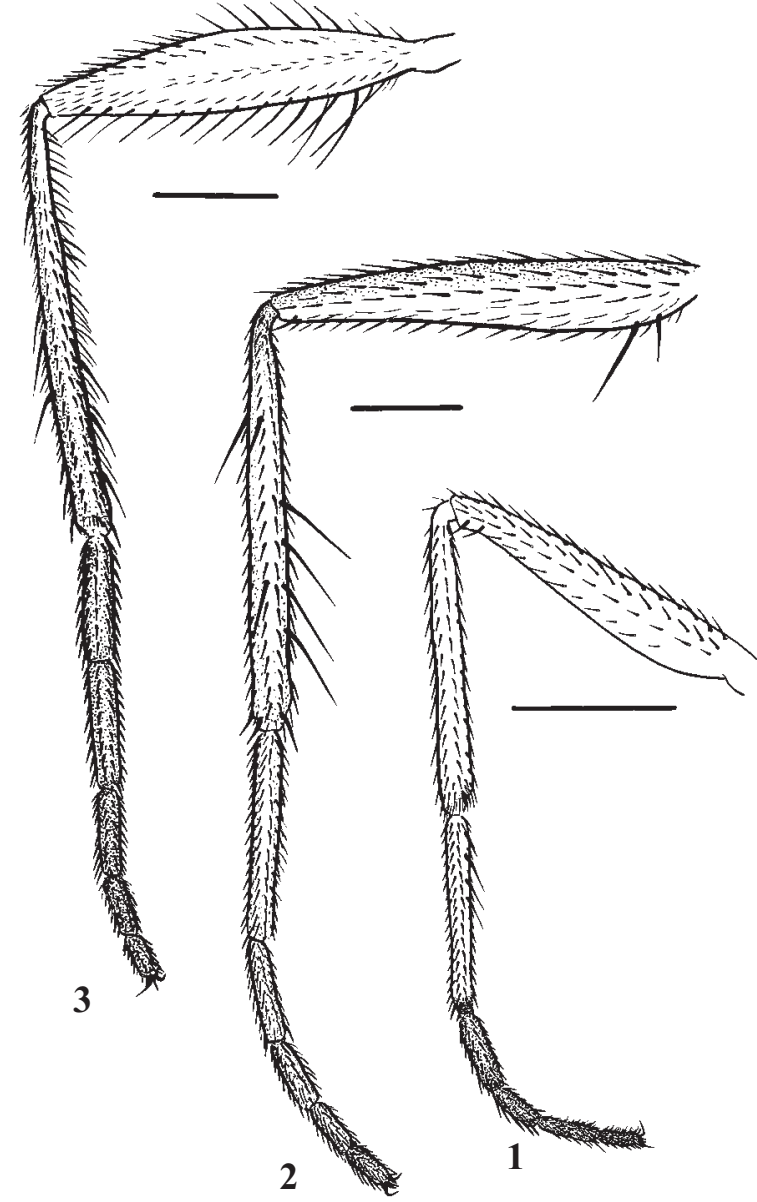

Figs 1-3. Teuchophorus israelensis sp.n.: 1 - fore leg; 2 mid leg; 3 - hind leg. Scale bar - $0.2 \mathrm{~mm}$

Рис. 1-3. Teuchophorus israelensis sp.n.: 1 - передняя нога; 2 - средняя нога; 3 - задняя нога. Масштаб - 0,2 мм.

with 3-4 apical bristles. Mid tarsus simple. Length ratios of leg II: 50/48/24/11/8/7/5. Hind coxa with dark brown bristle, inserted at basal $1 / 3$. Hind femur with one strong anterior subapical bristle; with one anteroventral (from $1 / 5$ to $3 / 5$ ) and one posteroventral (from $1 / 5$ to apex) rows of strong brown bristles; basal antero-/posteroventral and distalmost posteroventral bristles longest, to 1.5 times as long as femur diameter. Hind tibia slightly thickened towards apex, with posteroventral row of bristles along entire length, about as long as diameter of tibia, stronger in distal half; with 3-4 dorsals in one row, with apical posteroventral yellow comb, and 2-3 strong apical bristles. Hind basitarsus with 1-2 short ventral bristles, with preapical posteroventral yellow comb. Length ratios of leg III: 50/53/12/17/10/7/7.

Abdomen. Bronze, with 6 visible segments, with black hairs and bristles, cylindrical; $2^{\text {nd }}-4^{\text {th }}$ sternites brown; $5^{\text {th }}$ sternite normally developed, slightly smaller than $4^{\text {th }}$ sternite; $6^{\text {th }}$ tergite half as long as $5^{\text {th }} ; 8^{\text {th }}$ segment left basodorsal in position. Hypopygium enclosed; epandrium concolorous with abdomen; surstylus dark brown, typical for European species; cercus small, roundish, yellow, densely haired.

Female. Unknown (it appears impossible to distinguish T. israelensis sp.n. females from females of other species inhabiting Israel). 
DIAGNOSIS. T. israelensis sp.n. is very close to T. chaetifemoratus, differing from the latter in presence of 3 4 strong ventral bristles on mid tibia and ventral row of bristly hairs on hind tibia. Mid and hind tibiae of T. chaetifemoratus have no conspicuous ventral setation.

Key to the Palearctic species of Teuchophorus and SUSChANIA (MALES)

1. Legs black; mid femur with 11-12 posteroventral bristles; hind tibia unmodified, without conspicuous ventral setation; body $1.5 \mathrm{~mm}$.................................. T. nigrescus

- Legs yellow, sometimes hind leg partly dark; mid femur with at most 3 posteroventral bristles at apex ............ 2

2. Costal callus (stigma) absent ........................................ 3

- Costal callus present ...................................................... 4

3. Ventral lobe of surstylus with 3 long ventral setae, of which 2 setae twice as long as 2 apical setae; body $1.1 \mathrm{~mm}$, wing $1.6 \mathrm{~mm}$.................................. Suschania stackelbergi

- Ventral lobe of surstylus with 1 ventral seta, as long as 2 apical setae; body $1.3-1.4 \mathrm{~mm}$, wing $1.7-1.9 \mathrm{~mm}$ (Fig. 28) ....................................................... T. sinensis

4. Postpedicel nearly twice longer than wide, with pointed apex; $1.8 \mathrm{~mm}$ (Fig. 29) ..................... T. tianmushanus

- Postpedicel short, not longer than wide, with rounded apex

Legs unmodified; femora and tibiae without strong ventra bristles; hind tibia with ventral row of bristly hairs, about as long as diameter of tibia; body 1.3-1.7 mm (Fig. 22) T. simplex

- At least some of femora and tibiae with strong ventral bristles; hind tibia often thickened distally and bearing modified setae ventrally.....

6. Hind femur with double row of long ventral bristles; hind tibia simple, without strong or modified ventral bristles ....... 7

- Hind femur with at most few preapical bristles; hind tibia usually thickened distally and bearing modified bristles ventrally

7. Mid and hind tibiae without conspicuous ventral setation; body 1.2-1.7 mm (Figs 30-31) ...... T. chaetifemoratus

- Mid tibia with ventral row of 3-4 strong bristles at middle; hind tibia with ventral row of bristly hairs, about as long as diameter of tibia; body $1.6 \mathrm{~mm}$ (Figs 1-3)

T. israelensis sp.n.

8. Hind tibia simple, without group of hairs or modified bristles ventrally.....

- Hind tibia distinctly swollen or thickened at least dista often curved, with modified bristles and/or group of dense hairs ventrally

9. Hind tibia with one long midventral bristle, about 4 time as long as diameter of tibia; antenna with scape and pedicel yellow; body $2.0-2.1 \mathrm{~mm}$ (Fig. 6)

T. monochaetus

- Hind tibia with ventral row of 6-8 long bristles, about 3 times as long as diameter of tibia; antenna with scape and pedicel black; body 1.4-1.5 mm (Fig. 21) .............. T. gissaricus

10. Hind tibia regularly thickened along entire length, straight, with comb-like structure in basal half ...................... 11

- Hind tibia gradually or abruptly thickened distally, usually curved, with modified bristles and/or group of dense hairs ventrally in distal half ............................................ 13

11. Hind tibia with black ventral bristles arranged in flat process at basal 1/4; body $1.75 \mathrm{~mm}$ (Figs 15-16) ....

- Hind tibia with ventral comb of thick blunt erect bristles at middle.
12. Hind tibia with comb of 3 equal-sized and 1 longish blunt bristles and 1 shorter acute bristle; body $1.7-1.8 \mathrm{~mm}$, wing 1.6-2.0 mm (Figs 4-5) ................. T. ussurianus

- Hind tibia with comb of 5 equal-sized blunt bristles in addition to longer bifurcate blunt bristle and distinctly longer branched process; body 1.75-2.0 mm (Figs 17-18) T. nigricosta

13. Hind tibia with modified (thick, blunt or flattened) bristles in distal half in addition to simple bristles and hairs ....................................................................... 14

- Hind tibia with only simple bristles in distal half, sometimes long and curved, and simple hairs, sometimes grouped in a tuft

14. Hind tibia with ventral row of 4 equal-sized blunt erect bristles right below middle, about as long as diameter of tibia; body $1.5 \mathrm{~mm}$ (Figs 26-27) ....... . T. quadrisetosus

- Hind tibia with only 2 unequal modified bristles or with fan of flattened bristles on short stem ............................ 15

15. Hind tibia with fan of flattened bristles on short stem right below middle; body $1.5 \mathrm{~mm}$ (Figs 9-10). T. calcaratus

- Hind tibia with 2 unequal modified bristles .............. 16

16. Hind tibia thickened in distal half, with 2 thin unequal modified bristles at middle; body $1.6 \mathrm{~mm}$ (Figs 7-8) ... T. pseudobipilosus

— Hind tibia thickened in distal third .............................. 17

17. Hind tibia with one strong spine and one very thin adjacent bristle at about $2 / 3$; apical swelling with sparse hairs; body $1.5-2.0 \mathrm{~mm}$ (Figs 13-14) .......... T. monacanthus

- Hind tibia with 2 blunt subequal bristles beyond $2 / 3$; apical swelling with dense hairs; body 1.5-2.0 mm (Figs 11-12) T. bisetus

18. Hind tibia abruptly thickened in distal third, without very long ventral bristles ............................................. 19

- Hind tibia gradually thickened in distal half, with at least one ventral bristle, about 4 times as long as diameter of tibia.

19. Hind tibia with a ventral tuft of 4-6 bristly hairs right before distal swelling; body $1.7 \mathrm{~mm}$ (Fig. 25) ....

T. cristulatus

- Hind tibia with a dense ventral tuft of fine hairs on distal swelling; body $1.25-1.5 \mathrm{~mm}$ (Fig. 19) .. T. spinigerellus

20. Hind tibia with ventral row of at least 5 long bristles increasing in length distally; body $2 \mathrm{~mm}$ (Fig. 20) ........

T. rozkosnyi

- Hind tibia with only 1-2 very long ventral bristles ... 21

21 . Hind tibia with one blunt ventral bristle at $1 / 4$, slightly longer than diameter of tibia; with one long ventral bristle at about 2/3, 4 times as long as diameter of tibia, with 4-5 half shorter bristles at its basis and followed by setal serration; body $1.28-1.44 \mathrm{~mm}$ (Fig. 23) .... T. samraouii

- Hind tibia devoid of ventral bristles in basal half; with 2 very long anteroventral bristles right beyond middle, 4-5 times as long as diameter of tibia, followed by tuft of about 7 bristly hairs; body $1.8 \mathrm{~mm}$ (Fig. 24) ....... T. bipilosus

ACKNOWLEDGEMENTS. We are sincerely grateful to Dr. A. Freidberg (Tel Aviv, Israel), Dr. P. Grootaert (Brussels, Belgium) and Dr. E. Ovsyannikova (St. Petersburg, Russia) for their help in any respect. Dr. Andrei Ozerov (Moscow, Russia) and late Dr Loïc Matile (Paris, France) kindly helped in furnishing an opportunity to study the collections of their Museums. Dr. M. Kechev (Plovdiv, Bulgaria) and Dr. A. Tonguç (Muğla, Turkey) kindly provided us with photos of $T$. chaetifemoratus and T. cristulatus used for drawings. Drs. S. Naglis (Zurich, Switzerland), D. Yang (Beijing, China) and P. Grootaert gave permission to repro- 


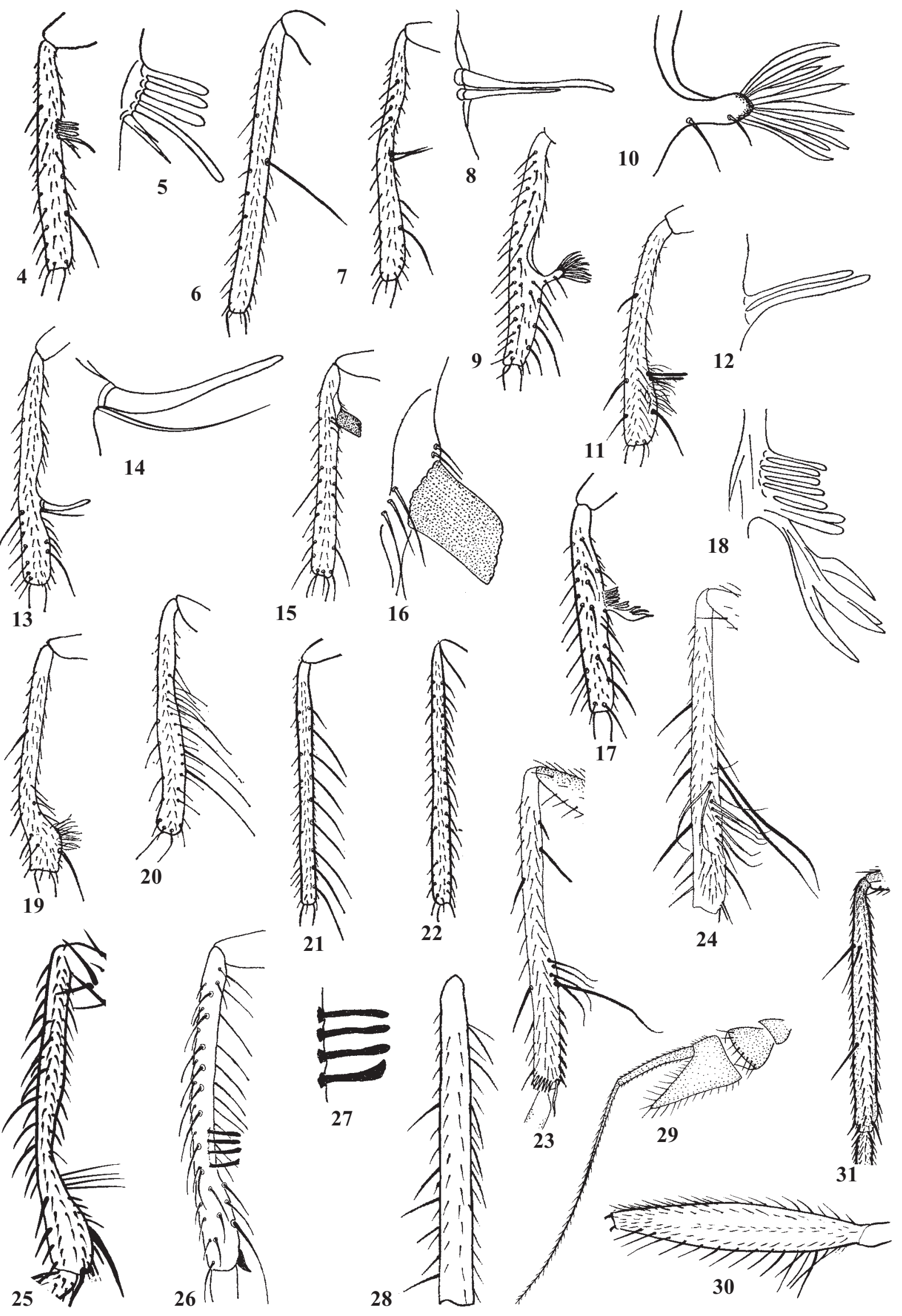


duce pictures of T. quadrisetosus, T. samraouii, T. sinensis and T. tianmushanus. Paper was supported by the grant of the Russian Foundation for Basic Research (РФФИ) No 11-0401051-a to Oleg P. Negrobov.

\section{References}

Becker T. 1908. Diptera der Kanarischen Inseln // Mitteilungen aus dem Museum für Naturkunde in Berlin. Vol.4. P.1-80.

Becker T. 1917-1918. Dipterologische Studien. Dolichopodidae. A. Paläarktische Region // Nova Acta Academiae Caesareae Leopodinisch-Carolinae Germanicae Naturae Curiosorum Vol.102(2)[1917]. P.113-361. Vol.103(3)[1918]. P.203-315. Vol.104(2)[1918]. P.35-214.

Bezzi M. 1903. Orthorrhapha Brachycera // Becker T., Bezzi M., Bischof J., Kertész K. \& Stein P. (eds.). Katalog der paläarktischen Dipteren. Volume II. Budapest. P.1-396.

Collin J.E. 1940. Critical notes on some recent synonymy affecting British species of Dolichopodidae (Dipt.) // Entomologist's Monthly Magazine. Vol.76 [=Ser.4. Vol.1]. P.261-271.

Cumming J.M. \& Wood D.M. 2009. Adult morphology and terminology [Chapter] 2 // Brown B.V., Borkent A., Cumming J.M., Wood D.M., Woodley N.E. \& Zumbado M.A. (eds.). Manual of Central American Diptera. Vol.1. Ottawa, Ontario, Canada: NRC Research Press. P.9-50.

Czerny L. \& Strobl G. 1909. Spanische Dipteren. III Beitrag // Verhandlungen der Kaiserlich-Königliche Zoologisch-botanischen Gesellschaft in Wien. Vol.5(59). P.121-301.

Grichanov I. Ya. 2003-2012. A check list of species of the family Dolichopodidae (Diptera) of the World arranged by alphabetic list of generic names. Available from http://grichanov.fortunecity.com/ Genera3.htm (accessed 5 March 2012).

Grichanov I.Ya. 2007. A checklist and keys to Dolichopodidae (Diptera) of the Caucasus and East Mediterranean // Plant Protection News Supplement. All-Russian Institute of Plant Protection, St. Petersburg. P.1-160.

Grichanov I.Ya. 2008. Afrotropical Sympycnus Loew (Diptera: Dolichopodidae) // International Journal of Dipterological Research. Vol.19. No.1. P.17-65.

Grichanov I.Ya., Selivanova O.V. \& Negrobov O.P. 2011. A brief synopsis of Palaearctic genera of the family Dolichopodidae (Diptera)// Ukrainska entomofaunistyka. Vol.2. No.2. P.11-40.

Grichanov I.Ya. \& Tomkovich K.P. 2009. New data on the distribution of Dolichopodidae (Diptera) in Azerbaijan // International Journal of Dipterological Research. Vol. 20. No.2. P.99-110.

Grootaert P., Stark A. \& Meuffels H.J.G. 1995. Notes on Mediterranean Teuchophorus species with the description of a new species from the nature reserve of El Kala, north east Algeria (Diptera, Empidoidea, Dolichopodidae) // Bulletin de l'Institut Royal des Sciences Naturelles de Belgique, Entomologie.Vol.65. P.109-113.

Kowarz F. 1868. Dipterologische Notizen II // Verhandlungen der K.-k. Zoologisch-Botanischen Gesellschaft in Wien. Vol.18. P.13-222.

Kowarz F. 1874. Die Dipteren-Gattung Chrysotus Meig // Verhandlungen der K.-k. Zoologisch-Botanischen Gesellschaft in Wien. Vol.24(Abh.). P.453-478.

Lim G.S., Hwang W., Kutty S.N., Meier R. \& Grootaert P. 2010. Mitochondrial and nuclear markers support the monophyly of Dolichopodidae and suggest a rapid origin of the subfamilies (Diptera: Empidoidea) // Systematic Entomology. Vol.35. P.59-70.
Loew H. 1857. Neue Beiträge zur Kenntniss der Dipteren. Fünfter Beitrag // Programme der Königlichen Realschule zu Meseritz. P. $1-56$.

Loew H. 1859. Neue Beiträge zur Kenntniss der Dipteren. Sechster Beitrag // Programme der Königlichen Realschule zu Meseritz. P.1-50.

Loew H. 1871. [Diptera of Turkestan] // Izvestiya Imperatorskogo obshchestva lyubitelei estestvoznaniya, antropologii i etnografii (Moscow). Vol.9. No.1. P.52-59 [in Russian].

Macquart J. 1827. Insectes diptères du nord de la France. Platypézines, dolichopodes, empides, hybotides. Lille. P.1-159.

Meigen J.W. 1824. Systematische Beschreibung der bekannten europäischen zweiflügeligen Insekten. Vol.4. Schultz-Wundermann, Hamburg. P.i-xii+1-428.

Meuffels H.J.G. \& Grootaert P. 1986. Dolichopodidae (Diptera) from Papua New Guinea IV: New species of the genus Teuchophorus Loew, 1857 // Indo-Malayan Zoology. Vol.3. No.2. P.217-262.

Meuffels H.J.G. \& Grootaert P. 1992. A new species of Teuchophorus (Diptera, Dolichopodidae) from Sicily // Animalia (Catania). Vol.17 [1990]. P.131-135.

Meuffels H. \& Grootaert P. 2004. The genus Teuchophorus in SouthEast Asia and New Guinea, description of new species, speciesgroups and their phylogeny (Insecta, Diptera, Dolichopodidae) // Journal of Natural History. Vol.38. P.143-258.

Mik J. 1880. Dipterologische Mittheilungen // Verhandlungen der K.-k. Zoologisch-Botanischen Gesellschaft in Wien. Vol.30 (Abh.). P.587-610.

Naglis S. 2009. New records of Sympycninae (Diptera, Dolichopodidae) from Turkey, with the description of a new species of Teuchophorus // Mitteilungen der Schweizerischen Entomologischen Gesellschaft. Vol.82. P.173-180.

Negrobov O.P. 1991. Dolichopodidae // Soos A., Papp L. \& Oosterbroeck P. (eds.). Catalogue of Palaearctic Diptera. Vol.7. Dolichopodidae-Platypezidae. Budapest: Akademiai Kiado. 291 p.

Negrobov O.P. \& Grichanov I.Ya. 1982. [New species of the family Dolichopodidae (Diptera) from Tajikistan and Kyrgyzstan] // Trudy Zoologicheskogo instituta AN SSSR. Vol.110. P.105108 [in Russian].

Negrobov O.P., Grichanov I.Ya. \& Shamshev I.V. 1984. [A review of Palearctic species of the genus Teuchophorus Loew (Dolichopodidae, Diptera)] // Nauchnye Doklady Vysshei Shkoly. Biologicheskie Nauki. No.9. P.37-42 [in Russian].

Olejníček J. 1981. A contribution to the knowledge of the family Dolichopodidae (Diptera) in Afghanistan with the description of two new species // Annotationes Zoologicae et Botanicae. Vol.140. P.1-6.

Parent O. 1925. Etude sur les Dolichopodidés de la collection Meigen conservées au Museum national d'Histoire Naturelle de Paris // Encyclopédie Entomologique. Ser.B II. Diptera, 2. P.41-58.

Pollet M. \& Kechev M. 2007. A review of Palaearctic Teuchophorus, with a new species from Bulgaria (Diptera, Dolichopodidae) // Zootaxa. No.1592. P.45-56.

Roser K.L.F. von. 1840. III. Beiträge zur Vaterlandskunde Erster Nachtrage zu dem im Jahre 1834 bekannte gemachten Verziechnisse in Württemberg vorkommender zweiflügliger Insekten // Correspondenzblatt der Landwirtschaft aus dem Vereins in Württemburg, Stuttgart. Vol.1(1)(Supplement 1). P.49-64.

Santos Abreu D.E. 1929. Monografia de los dolichopodidos de las Islas Canarias // Memorias de la Real Academia de Ciencias y Artes de Barcelona. Ser.3. Vol.21(17). P.1-124.

Stackelberg A.A. 1927. Dolichopodidae turanicae novae vel minus cognita // Konowia. Vol.6. P.225-233.

Figs 4-31. Teuchophorus sp.: 4-5 - T. ussurianus; 6-T. monochaetus; 7-8 - T. pseudobipilosus; 9-10 - T. calcaratus; 11-12T. bisetus; $13-14-$ T. monacanthus; $15-16-$ T. rohdendorfi $; 17-18-$ T. nigricosta $; 19-$ T. spinigerellus; $20-$ T. rozkosnyi; $21-$ T. gissaricus; $22-$ T. simplex; $23-$ T. samraouii; $24-$ T. bipilosus; $25-$ T. cristulatus; $26-27-$ T. quadrisetosus; $28-$ T. sinensis; 29 - T. tianmushanus; 30-31 - T. chaetifemoratus; 4-28 - hind tibia; 29 - antenna; 30 - hind femur; $31-$ mid tibia.

Рис. 4-31. Teuchophorus sp.: 4-5 - T. ussurianus; 6-T. monochaetus; 7-8 - T. pseudobipilosus; 9-10 - T. calcaratus; 11-12T. bisetus; 13-14 - T. monacanthus; 15-16 - T. rohdendorfi; 17-18 - T. nigricosta; $19-$ T. spinigerellus; $20-$ T. rozkosnyi; $21-T$. gissaricus; $22-$ T. simplex; $23-$ T. samraouii; $24-$ T. bipilosus; $25-$ T. cristulatus; $26-27-$ T. quadrisetosus; $28-$ T. sinensis; $29-$ T. tianmushanus; 30-31 - T. chaetifemoratus; 4-28 - задняя голень; 29 - усик; 30 - заднее бедро; 31 - средняя голень. 
Tsacas L. 1960. Sur quelques Diptères de l'ile Majorque// Eos. Revista espanola de Entomologia (Madrid). Vol.36. No.2. P.237-244.

Vaillant F. 1952. Quelques Dolichopodidae de la zone paléarctique (Diptera) // Bulletin de l'Institut Royal des Sciences Naturelles de Belgique, Entomologie. Vol.28(65). P.1-15.

Walker F., Stainton H.T. \& Wilkinson S.J. (Eds.). 1851. Insecta Britannica, Diptera. Vol.1. P.1-314.

Yang D. 2002. Diptera: Dolichopodidae // Wu Hong \& Pan Chengwen (eds.). Insects of Tianmushan National Nature Reserve (2001). P.429-441 [in Chinese with English summary].

Yang D. \& Saigusa T. 2000. New species of Dolichopodidae from Henan (Diptera: Empidoidea) // Xiaocheng S. \& Haichao P.
(eds.).The fauna and taxonomy of insects in Henan, vol. 4. Insects of the Mountains Funiu and Dabie regions. P.189-210 [in Chinese, with English summary].

Yang D., Zhu Y., Wang M. \& Zhang L. 2006. World Catalog of Dolichopodidae (Insecta: Diptera). Beijing: China Agricultural University Press. 704 p.

Zetterstedt J.W. 1843. Diptera Scandinaviae disposita et descripta. Officina Lundbergiana, Lundae [= Lund]. Vol.2. P.441894.

Zetterstedt J.W. 1849. Diptera Scandinaviae disposita et descripta. Officina Lundbergiana, Lundae [= Lund]. Vol.8. P.29353366. 